\title{
Reports
}

\section{Recalibrating global health: how COVID-19 can bring us together}

\author{
Hloni Bookholane ${ }^{1} \mathbb{0}$, Dominique Vervoort ${ }^{2} \mathbb{Q}^{\text {, }}$ Malvikha Manoj ${ }^{3}$, Daniella Malave-Trowbridge ${ }^{4}$, Desmond T. Jumbam $^{5}$ \\ (1D) \\ 1 Department of Medicine, Groote Schuur Hospital, University of Cape Town, Cape Town, South Africa, 2 Department of Health Policy and \\ Management, Johns Hopkins Bloomberg School of Public Health, Baltimore, Maryland, United States, ${ }^{3}$ Department of International Health, Johns \\ Hopkins Bloomberg School of Public Health, Baltimore, Maryland, United States, ${ }^{4}$ Center for Humanitarian Health, Johns Hopkins Bloomberg School \\ of Public Health, Baltimore, Maryland, United States, 5 Health Policy and Advocacy, Operation Smile, Accra, Ghana \\ Keywords: politics, health systems, global health \\ https://doi.org/10.29392/001c.25474
}

\section{Journal of Global Health Reports}

Vol. 5, 2021

Global health is at a crossroads. The COVID-19 pandemic has highlighted major flaws in the institutions and ideals that engender global health. If we, as a global community, are to achieve the noble goals we set for ourselves to end poverty, prevent suffering, and promote health and well-being, we have to re-examine these ideals and the aspects of global health that corrupt the system. Pre-COVID-19 health challenges are compounded by a global pandemic that very few nations have a handle on today. They will continue to perpetuate further cycles of stress on the health system, if left unattended.

The COVID-19 pandemic has highlighted ${ }^{1}$ pre-existing health systems, health equity, governance, and humanitarian problems. ${ }^{2}$ Neglected tropical diseases, climate change, and limited access to safe surgical healthcare are global health problems begging for attention. Yet, from lack of appropriate investments, insufficient and sometimes corrupted data and monitoring infrastructure, ${ }^{3}$ to disinformation, several forces have led to global attention not matching actual needs. ${ }^{4,5}$ Moreover, humanitarian health emergencies receive inadequate coordinated global efforts to mitigate the dire straits many nations are in. ${ }^{6}$ This underscores the need to re-imagine health systems that work for all, not just for some. Whether the impetus to decisively act on them was not politically advantageous (enough), academically prestigious (enough), worthy of a (high impact) publication, or something else entirely, the writing is on the wall: we should have done better. We need to do better going forward.

Low- and middle-income countries (LMICs) face a high burden of communicable diseases, non-communicable diseases (NCDs), and rising injuries, whereas high-income countries (HICs) deal with a higher and continuously growing burden of NCDs. In spite of this, global health priorities have predominantly been driven by academics, funders, politicians, and organizations in HICs resulting in critical healthcare needs in LMICs falling through the cracks. For example, despite over $85 \%$ of all NCD-related deaths occurring in LMICs, ${ }^{7}$ most discourse around NCDs is centered around NCD burdens in HICs. Many in HICs may be surprised that neglected tropical diseases like leprosy still cause much morbidity and mortality in LMICs. ${ }^{8}$ Similarly, despite infectious diseases like tuberculosis receiving an increasing amount of much needed funding, 1.8 million people still die per annum. Moreover, nearly 5 billion ${ }^{9}$ people worldwide lack access to essential surgical services, yet only $1 \%$ of development assistance for health goes towards addressing these gaps. ${ }^{10}$ These are all health system problems which preceded the pandemic, and have been worsened to varying degrees due to faltering global attention and investments.

The COVID-19 pandemic and its mismanagement have highlighted important factors influencing the noble pursuit of equitable access to healthcare: lack of political will, politicization of non-political matters, ${ }^{11}$ and inconsistent and incompatible global health agendas. Power imbalances and the exclusion of certain important demographic groups in global health can and does have trickle-down effects at every level of the ecosystem, causing an asymmetry between perceived and actual needs. ${ }^{12,13}$

Although the body of knowledge on health systems strengthening in LMICs is growing, much of this research is led by researchers from HICs with access to research funds. ${ }^{14}$ Without sufficient engagement with local researchers and stakeholders, this often leads to poor or incomplete understanding of the needs and context of those being "studied." Consequently, the purported beneficiaries of global health programs (i.e., those in LMICs) remain on the periphery, while "experts"' from HICs set programs, priorities, and agendas in LMICs. Moreover, while HIC global health academics focus on problems elsewhere ${ }^{15}$ they often neglect problems in their own communities through the institutional and academic hubris that global health problems "exist elsewhere and never at home," another factoid that COVID-19 has debunked.

Pandemic preparedness includes and requires global health agendas to be adequately addressed. ${ }^{16}$ One could argue that a priori health system strengthening and universal healthcare coverage would have resulted in less morbidity and mortality during the pandemic. This is especially true when we take into account the unmet need for healthcare delivery, as a result of shifting all focus to the pandemic. Moreover, meaningful local and international government investment towards resilient health systems is less costly and more sustainable ${ }^{17}$ than heuristic and political spending which is mindlessly more "justified." COVID-19 has highlighted countries that, despite relatively robust capacities and resources, failed to appropriately respond to the pandemic primarily due to weak or fragmented leadership and mistrust in government and science, among oth- 
ers. ${ }^{18}$ As such, global health appears to be a contest in which within certain countries, the wherewithal to address the fundamental threats to our global health and safety exist, but the know-do gap remains wide.

Global health is a necessary pursuit as we collectively try to improve access to healthcare and equity therein; practically, however, it is not fit for purpose. The access to and distribution of COVID-19 vaccines are a cautionary tale of the limits of the ideals of what global health aims to achieve. If anything, it is the stage on which institutional hubris, academic imperialism, and geopolitics are played out. ${ }^{19}$ In the deep trenches of a global pandemic, health equity is an ideal that seems unattainable. If the global community cannot work together now during a pandemic, the failures of the past truly make sense. Have we overestimated the ideals of altruism and collaboration, and underestimated the traits of nationalism and egocentrism on the part of global health stakeholders? Those in positions of power and influence-world leaders, international and national organizations, high impact academic journals, highly regarded institutions, and local decision-making bodies-need to make a unanimous and coordinated commitment to prioritize continuously neglected populations and global health problems. Moreover, we need to do better in terms of anticipating and engaging in politics and governance. It cannot be left to science or chance alone that the right priorities be set: everyone who cares about health needs to get involved in politics at various levels to help shape global health. Quality data and evidence-driven decision making, grounded in equity and community engagement and mobilization must be the north star that guides the direction of public practice locally and globally - not the will of a few. Finally, greater investment in universal healthcare is required to buttress the fragile and growing health systems around the world. The pandemic has shown the world what fragmentation, nationalism, and politicized division result in; there may exist a glimpse of hope, even if naive, for a future of collaboration, multicultural globalization, and political unity. Failing to do so again will be catastrophic and unrepairable.

\section{FUNDING}

None.

\section{AUTHORSHIP CONTRIBUTIONS}

HB: Conceptualization, Writing, Review, and Approval. DV: Writing, Review, and Approval. MM: Writing, Review, and Approval. DMT: Writing, Review, and Approval. DTJ: Writing, Review, and Approval.

\section{COMPETING INTERESTS}

The authors completed the Unified Competing Interest form at www.icmje.org/coi disclosure.pdf (available upon request from the corresponding author) and declare no conflicts of interest.

\section{CORRESPONDENCE TO:}

\section{Hloni Bookholane, MBChB MPH}

Department of Medicine, Groote Schuur Hospital, University of Cape Town

Main Road, Observatory, 7925 Cape Town, South Africa

Submitted: June 06, 2021 GMT, Accepted: June 23, 2021 GMT 


\section{REFERENCES}

1. Lambert H, Gupte J, Fletcher H, et al. COVID-19 as a global challenge: towards an inclusive and sustainable future. The Lancet Planetary Health. 2020;4(8):e312-e314. doi:10.1016/s2542-5196(20)301 $\underline{68-6}$

2. CARE International. The 10 most under-reported humanitarian crises of 2020. CARE International. Published online 2021. https://www.careinternationa l.org.uk/stories/10-most-under-reported-humanitaria n-crises-2020

3. Warren AE, Wyss K, Shakarishvili G, Atun R, de Savigny D. Global health initiative investments and health systems strengthening: a content analysis of global fund investments. Globalization and Health. 2013;9(1):1-14. doi:10.1186/1744-8603-9-30

4. Abbasi K. Covid-19: politicisation, “corruption," and suppression of science. BMJ. Published online 2020. doi:10.1136/bmj.m4425

5. Nguyen A, Catalan D. Digital mis/disinformation and public engagment with health and science controversies: fresh perspectives from Covid-19. Media and Communication. 2020;8(2):323-328. doi:1 $0.17645 / \mathrm{mac} . v 8 \mathrm{i} 2.3352$

6. Spiegel PB. The humanitarian system is not just broke, but broken: recommendations for future humanitarian action. The Lancet. Published online 2017. doi:10.1016/s0140-6736(17)31278-3

7. World Health Organization. Noncommunicable diseases: World Health Organization. Published 2018. Accessed April 9, 2021. https://www.who.int/news-ro om/fact-sheets/detail/noncommunicable-diseases

8. Pai M. Record Funding For Global Health Research, But Neglected Tropical Diseases Remain Neglected: Forbes. Published 2020. Accessed April 9, 2021. http s://www.forbes.com/sites/madhukarpai/2020/01/29/re cord-funding-for-global-health-research-but-neglect ed-tropical-diseases-remain-neglected/?sh $=5 \mathrm{f} 5 \mathrm{~b} 499 \mathrm{~d}$ $\underline{3 c 8 e}$

9. Alkire BC, Raykar NP, Shrime MG, et al. Global access to surgical care: a modelling study. The Lancet Global Health. 2015;3(6):e316-e323. doi:10.1016/s221 4-109x(15)70115-4
10. Dieleman JL, Yamey G, Johnson EK, Graves CM, Haakenstad A, Meara JG. Tracking global expenditures on surgery: gaps in knowledge hinder progress. The Lancet Global Health. 2015;3:S2-S4. do i:10.1016/s2214-109x(15)70075-6

11. Vervoort D, Bookholane H. COVID-19 Isn't Political; Its Response Shouldn't Be Politicized: Johns Hopkins Bloomberg School of Public Health Global Health NOW. Published 2021. Accessed April 9, 2021. https://www.globalhealthnow.org/2021-01/covid-19-i snt-political-its-response-shouldnt-be-politicized

12. Health TL. Decolonising COVID-19. The Lancet Global Health. 2020;8(5):e612. doi:10.1016/s2214-109 $\underline{\mathrm{x}(20) 30134-0}$

13. Global Health 50/50, "The Global Health 50/50 Report 2020: Power, Privilege and Priorities.”; 2020.

14. Adam T, Ahmad S, Bigdeli M, Ghaffar A, Røttingen JA. Trends in Health Policy and Systems Research over the Past Decade: Still Too Little Capacity in LowIncome Countries. PLOS ONE. 2011;6(11):e27263. do i:10.1371/journal.pone.0027263

15. Turcotte-Tremblay AM, Fregonese F, Kadio K, Alam N, Merry L. Global health is more than just 'Public Health Somewhere Else.' BMJ Global Health. 2020;5(5):e002545. doi:10.1136/bmigh-2020-002545

16. Rushton S. Global Health Security: Security for Whom? Security from What? Political Studies. 2011;59(4):779-796. doi:10.1111/j.1467-9248.2011.00 919.x

17. Harrabin R. Cheaper to prevent pandemics than "cure" them. BBC News. Published online 2020. Accessed April 9, 2021. https://www.bbc.com/news/sc ience-environment-54721687

18. Nuzzo JB, Bell JA, Cameron EE. Suboptimal US Response to COVID-19 Despite Robust Capabilities and Resources. JAMA. 2020;324(14):1391-1392. doi:1 $\underline{0.1001 / j a m a .2020 .17395}$

19. Taylor S. 'Global health': meaning what? BMJ Global Health. 2018;3(2):e000843. doi:10.1136/bmig h-2018-000843 